\title{
La Arqueología del ocio y de la vida cotidiana da título a las V Jornadas Cordobesas de Arqueología Andaluza
}

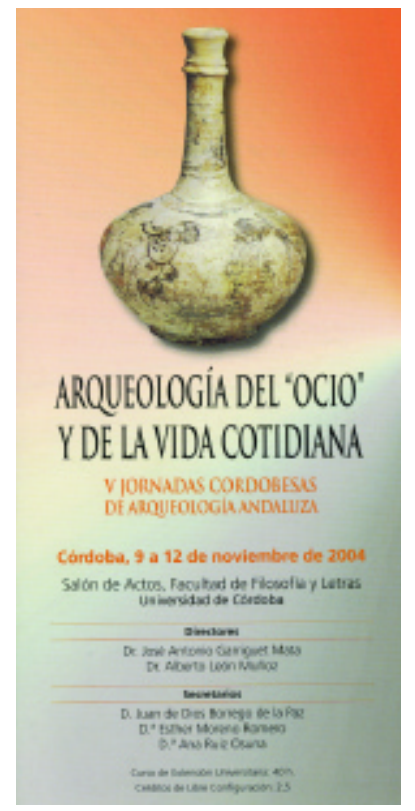

Entre los días 9 a 12 de noviembre de 2004 se celebraron en Córdoba las V Jornadas Cordobesas de Arqueología Andaluza, organizadas por el Seminario de Arqueología de la Universidad de Córdoba. El título de las jornadas en 2004, que registraron casi 200 inscritos, fue Arqueología del "ocio" y de la vida cotidiana.

En las jornadas han participado investigadores procedentes de diversas universidades españolas, como la Carlos III de Madrid, la Universidad de Sevilla o Castilla La Mancha. Asimismo, se ha contado con la presencia del CSIC. Por otro lado, han intervenido también expertos pertenecientes a otras instituciones, como el conjunto arqueológico Madinat al-Zahra y el Museo Arqueológico y Etnológico Provincial de Córdoba. Igualmente participaron los responsables y miembros del amplio equipo de investigación surgido en la capital cordobesa a raíz del convenio firmado en 2001 entre la Gerencia Municipal de Urbanismo del Ayuntamiento de Córdoba y la Universidad de Córdoba (representada por su Seminario de Arqueología) para la realización de actividades arqueológicas en la ciudad. Finalmente, como reflejo de la interdiciplinariedad que siempre debe estar presente en la ciencia arqueológica, tomaron también la palabra profesionales de la antropología, la física e incluso la cirujia.

De manera paralela, las sesiones de trabajo celebradas en la Facultad de Filosofía y Letras tuvieron lugar, como viene siendo habitual desde que estas jornadas se celebraron por primera vez en 1997 bajo la denominación de Jornadas Cordobesas de Arqueología, la realización de una serie de itinerarios a través de los que conocer de forma directa distintas zonas de interés arqueológico de la ciudad. En esta ocasión, al igual que en ediciones anteriores, los itinerarios fueron guiados por miembros de la Universidad y del convenio antes mencionado, ofreciendo a los inscritos la posibilidad de visitar la muralla occidental, con algunos de los monumentos funerarios que se conservan a sus pies, como los reconstruidos frente a la antigua Puerta de Gallegos; el entorno del río, comprendiendo el Alcázar de los Reyes Cristianos, la muralla de la Ribera y el arrabal de Secunda; el yacimiento de Cercadilla; y el templo de la calle Claudio Marcelo y Museo Arqueológico de Córdoba.

La vida cotidiana estuvo presente en estas Jornadas con un desarrollo diacrónico, iniciándose en momentos prerromanos y llegando hasta época medieval. Los bloques en los que se estructuraron las conferencias agilizaron el desarrollo de las mismas y concentraron la atención en multitud de temas, como "Juegos, luchas, carreras...: diversión y ocio en la ciudad", "Dioses, cultos y cre- encias: entre el pragmatismo y la fe", "Del hogar al taller", "... y la Muerte llamó a su puerta", para época romana; y "De la casa al baño pasando por la Mezquita", para el mundo medieval. Así pues, estas Jornadas permitieron un acercamiento a aspectos de la Arqueología que en pocas ocasiones se ponen de manifiesto, o bien permanecen desdibujados bajo los grandes hallazgos protagonizados por estructuras y edificios que conformaban las ciudades antiguas.

El hecho de que las $V$ Jornadas mostraran aspectos relacionados con la vida diaria y la cotidianidad en la Antigüedad destaca la importancia de los datos en Arqueología, exige siempre un registro exhaustivo de toda la información procedente de las excavaciones con la elaboración de informes detallados, así como la multidisciplinariedad de la ciencia arqueológica, una vez más, resaltando en esta ocasión los hallazgos que no suelen trascender en las publicaciones divulgativas, quedando habitualmente en los círculos académicos.

También han permitido una extrapolación de tales circulos para llegar a la sociedad en general, potenciando otras formas de aproximación al Patrimonio Arqueológico, título éste de la conferencia de clausura impartida por Desiderio Vaquerizo, donde se insistía en que el fin último de la Arqueología es la difusión, no sólo científica sino también divulgativa, donde la vida cotidiana deberá jugar un papel preponderante. Máxime si tenemos en cuenta que estos datos son un recurso importante para dar a conocer la Arqueología a todos los sectores de la sociedad de forma cercana y curiosa, suscitando gran interés. Algo que se observó en la buena acogida que ha tenido esta edición, a la que han asistido personas procedentes de distintos puntos de Andalucia y del resto de España.

Gracias a las conferencias e itinerarios celebrados se puso de manifiesto la riqueza arqueológica de Córdoba, pero también la necesidad de dar a conocer ese patrimonio con más iniciativas por parte de la administración pública para divulgarlo, con la deseada creación en un futuro no muy lejano de "Parques Arqueológicos", apuesta fundamental para el acercamiento de la Arqueología a la sociedad en general, y con la configuración de itinerarios didácticos, conferencias divulgativas y exposiciones en los que todos los sectores sociales y económicos deben participar.

Juan de Dios Borrego, Esther Moreno y Ana Ruiz

Secretarios de las Jornadas 